\title{
CLINICAL EPIDEMIOLOGY AND MANAGEMENT OF EXTRADURAL HAEMORRHAGE IN RURAL INDIA
}

\author{
Neha S. Jadhav1, Avinash S. K², Amol B. Kamble ${ }^{3}$
}

${ }_{1}^{1}$ MCh Resident, Department of Neurosurgery, KEM, Mumbai, Maharashtra, India.

${ }^{2}$ Senior Resident, Department of General Surgery, GMCH, Miraj, Maharashtra, India.

3 Assistant Professor, Department of General Surgery, GMCH, Miraj, Maharashtra, India.

\section{ABSTRACT}

\section{BACKGROUND}

Among the top ten causes of mortality in India, head injury was the tenth cause two decades back. But with increasing urban expansion and lifestyle changes, trauma will occupy the fifth position in the list of major killers and third position among causes of disease burden in 2020.

The aim of this study was to analyse the clinical spectrum and to evaluate the postoperative outcome in patients with head injury with an extradural haematoma (EDH).

\section{MATERIALS AND METHODS}

This was a retrospective observational study which included 100 patients admitted in our Government Medical College, Miraj, Maharashtra, India over the past two years (01/06/2016 to 30/05/2018) with head injury, diagnosed to have traumatic Extradural Haemorrhage (EDH). A detailed clinical history was taken, physical examination done and CT scan performed in all patients. For patients who were subjected to surgery, operative and post-operative findings were noted.

\section{RESULTS}

Maximum patients suffering from EDH are in the age group of 21 - 40 years (56\%) with male predominance (82\%). Most common mode of injury is RTA (60\%) under the influence of alcohol. Majority of cases reached hospital within 12 hours from time of injury (75\%). 60\% of patients with EDH presented with Loss of Consciousness (LOC) followed by vomiting in $70 \%$ of cases followed by Headache in $45 \%$ of cases. $58 \%$ of the cases presented with mass effect over brain parenchyma with frontotemporoparietal EDH as the most common location. Out of 100 cases, surgical approach was considered in 52 patients, while remaining 48 patients were managed conservatively.

\section{CONCLUSION}

Early presentation, with GCS in between 9 - 15, has good clinical outcome.

\section{KEY WORDS}

Epidural Haematoma (EDH), Loss of Consciousness (LOC), Rural India.

HOW TO CITE THIS ARTICLE: Jadhav NS, Avinash SK, Kamble AB. Clinical epidemiology and management of extradural haemorrhage in rural India. J. Evolution Med. Dent. Sci. 2018;7(35):3821-3824, DOI: 10.14260/jemds/2018/857

\section{BACKGROUND}

India is undergoing major economic and demographic transition coupled with increasing urbanisation and motorisation. Among the top ten causes of mortality in the country, head injury was the tenth cause two decades back. But with the increasing urban expansion and lifestyle changes, trauma will occupy the fifth position in the list of major killers and third position among causes of disease burden in 2020.1,2,3,4

Epidural haematomas occur most commonly after a head trauma, which may cause a temporary loss of consciousness or a coma. The trauma often involves the temporal lobe and leads to tearing of the middle meningeal artery. It can also occur from rupture of the anterior meningeal artery or the dural venous sinuses.5,6,7

'Financial or Other Competing Interest': None.

Submission 26-07-2018, Peer Review 14-08-2018,

Acceptance 16-08-2018, Published 27-08-2018.

Corresponding Author:

Amol B. Kamble,

T1, Laxmivallabh Apartment,

Mangalamurthy Colony, Near Vasvade Hospital,

Near Reliance Market, Sangli-416416,

Maharashtra, India.

E-mail: amu.kamble@gmail.com

DOI: $10.14260 /$ jemds $/ 2018 / 857$

\section{(c) $(\mathbf{P})$}

The majority of cases are accompanied by skull fracture. EDH may be associated with a transient period of consciousness, also known as a "lucid interval," after the initial loss of consciousness due to the primary brain injury. Following this "lucid interval," rapid deterioration due to blood accumulation may cause headache, vomiting, drowsiness, confusion, aphasia, seizures and hemiparesis.8,9,10 If the haematoma remains unresolved, potential complications include Increased Intracranial Pressure (ICP), ipsilateral dilated pupil due to compression of the oculomotor nerve.

Currently, EDH represents about $1 \%$ to $5.5 \%$ of intracranial lesions in patients with traumatic brain injury, its mortality reaching 20\%. Despite the small percentage of patients with head trauma developing EDH, the rapid neurological deterioration observed is often dramatic.11,12 Early diagnosis and neurosurgical intervention in a timely manner promote the reduction of morbidity and mortality, so it is vital that people who deal with trauma patients are familiar with and trained to manage this type of injury. ${ }^{13,14,15}$

\section{Aim of the Study}

The aim of this study was to analyse various causes, clinical presentations, factors influencing presentations and to evaluate the postoperative outcome in patients with head injury with an extradural haematoma before surgery and to formulate recommendations for improvement of therapy and 
suggestions for the future.

\section{MATERIALS AND METHODS}

This is a prospective observational study, which included 100 patients admitted in Government Medical College over the past two years $(01 / 06 / 2016$ to $30 / 06 / 2018)$ with head injury, diagnosed to have traumatic extradural haemorrhage.

\section{Inclusion Criteria}

- All patients between age groups of 5 to 70 years were included.

- Study included evaluation of traumatic extradural haemorrhage.

\section{Exclusion Criteria}

- Long-term outcome excluded.

- Patients bearing associated injury to chest, abdomen and extremities were excluded.

\section{Methods}

- A detailed history with regards to-
a. Time of incident.
b. Alcohol influence.
c. Mode of injury.
d. Time of arrival to hospital.

- All patients subjected to thorough initial clinical examination.

- $\quad$ All patients were subjected to emergency and follow-up CT scan plain- Brain.

- Patients were operated, operative finding noted, postoperatively records were analysed.

- The study evaluated initial outcome, excluding long-term outcome.

\section{RESULTS}

Total 100 cases were included in the study.

\section{Age Distribution}

This study revealed that maximum patients suffering from EDH were in the age group of 21 - 40 years (56\%). The details of age incidences are given in Table 1.

\begin{tabular}{|c|c|}
\hline Age in Years & Number \\
\hline $5-20$ & 26 \\
\hline $21-40$ & 56 \\
\hline $41-60$ & 14 \\
\hline $61-80$ & 4 \\
\hline \multicolumn{2}{|c|}{ Table 1. Age Distribution } \\
\hline
\end{tabular}

\section{Sex Distribution}

This study showed that males were predominant as compared to females. Out of 100 cases 82 were males (82\%), whereas 18 cases were females (18\%) (Table 2).

\begin{tabular}{|c|c|}
\hline Sex & Number (N= 100) \\
\hline Male & 82 \\
\hline Female & 18 \\
\hline \multicolumn{2}{|c|}{ Table 2. Sex } \\
\hline
\end{tabular}

\section{Mode of Injuries}

This study revealed that most common mode of injury was RTA $(60 \%)$ and $66.67 \%$ of cases occurred under the influence of alcohol. The details of mode of injuries is shown in Table 3.

\begin{tabular}{|c|c|}
\hline Mode of Injury & Number (N= 100) \\
\hline RTA & 60 \\
\hline RTA with Alcohol & 40 \\
\hline RTA without Alcohol & 20 \\
\hline Accidental Fall & 25 \\
\hline Assaults & 15 \\
\hline \multicolumn{2}{|c|}{ Table 3. Mode of Injuries } \\
\hline
\end{tabular}

\section{Time of Arrival}

Majority of cases reached hospital within 12 hours from the time of injury as shown in Table No. 4.

\begin{tabular}{|c|c|}
\hline Time of Arrival & Number (N= 100) \\
\hline$<12$ hours & 75 \\
\hline$>12$ hours & 25 \\
\hline \multicolumn{2}{|c|}{ Table 4. Time of Arrival } \\
\hline
\end{tabular}

\section{Clinical Presentations}

Majority of patients with EDH presented with vomiting in $70 \%$ cases followed by LOC in $60 \%$ of cases followed by headache in $45 \%$ of cases as shown in Table 5.

\begin{tabular}{|c|c|}
\hline Symptom & Number $(\mathrm{N}=100)$ \\
\hline With LOC & 60 \\
\hline Without LOC & 40 \\
\hline Headache & 45 \\
\hline Vomiting & 70 \\
\hline ENT Bleeding & 38 \\
\hline Convulsion & 8 \\
\hline Hemiparesis & 13 \\
\hline \multicolumn{2}{|c|}{ Table 5. Clinical Presentations } \\
\hline
\end{tabular}

\section{Glasgow Coma Score}

Majority of cases were presented with GCS 15, i.e. 42\% shown in Table 6.

\begin{tabular}{|c|c|}
\hline GCS & Number $(\mathbf{N}=\mathbf{1 0 0})$ \\
\hline 15 & 42 \\
\hline $13-14$ & 24 \\
\hline $9-12$ & 20 \\
\hline $5-8$ & 8 \\
\hline $3-4$ & 6 \\
\hline \multicolumn{2}{|c|}{ Table 6. Glasgow Coma Score } \\
\hline \multicolumn{2}{|c|}{}
\end{tabular}

Patients with GCS, 15 accounts for $42 \%$ followed by GCS in between 9 - 13 which is $44 \%$.

\section{EDH with or without Mass Effect}

Out of 100 cases, 58 cases presented with mass effect over brain parenchyma and 42 cases presented without mass effect.

\section{Presentation of EDH}

Out of 100 cases, $40 \%$ of the cases presented as pure isolated EDH. $40 \%$ of cases presented with associated fracture. Remaining $15 \%$ of cases presented with associated brain parenchymal injury shown in Table 7.

\begin{tabular}{|c|c|}
\hline Presentation & Number (N= 100) \\
\hline Pure Isolated EDH & 40 \\
\hline Associated Fracture & 45 \\
\hline Associated Brain Injury & 15 \\
\hline \multicolumn{2}{|c|}{ Table 7. Presentation of EDH } \\
\hline
\end{tabular}




\section{Pupil Status}

Majority of cases presented with equally reacting pupils at time of presentation to hospital, i.e. $70 \%$. Details are shown in Table 8.

\begin{tabular}{|c|c|}
\hline Pupil Status & Number N= 100 \\
\hline Equal/reactive & 70 \\
\hline Unequal/non-reactive & 20 \\
\hline Bil. dilated/non-reactive & 10 \\
\hline \multicolumn{2}{|c|}{ Table 8. Pupil Status } \\
\hline
\end{tabular}

\section{EDH Location}

The dominant type of EDH observed in the study was frontal presenting in $36 \%$ cases followed by temporal in $21 \%$ cases, next only is temporal parietal in $10 \%$ cases. Posterior fossa EDH presentation was relatively less found in $5 \%$ as occipital shown in Table 9.

\begin{tabular}{|c|c|}
\hline Location of EDH & Number (N= 100) \\
\hline Frontal & 10 \\
\hline Temporal & 10 \\
\hline Occipital & 4 \\
\hline Parietal & 10 \\
\hline Fronto-temporal & 8 \\
\hline Fronto-temporoparietal & 25 \\
\hline Temporoparietal & 20 \\
\hline Parieto-occipital & 5 \\
\hline Fronto-parietal & 8 \\
\hline \multicolumn{2}{|c|}{ Table 9. Location of EDH } \\
\hline
\end{tabular}

Fronto-temporoparietal EDH is the most common, i.e. $25 \%$. The dominant type of EDH observed in the study was fronto-temporoparietal presenting in $25 \%$ cases followed by temporoparietal in $20 \%$ cases.

\section{Treatment}

Out of 100 cases surgical approach was considered in 52 patients, while remaining 48 patients were managed conservatively.

\section{Outcome}

88 patients were recovered, whereas 12 patients died.

\section{DISCUSSION}

A total of 100 cases of extradural haemorrhage were registered during the period of study and out of these $60 \%$ cases were of RTA, 25\% cases were of accidental fall and 15\% cases were of assault. In this study, the most common age group was 21 - 40 years (56\%). Incidence of head injury was more in age range of 21 to 40 years with $56 \%$ cases as compared to both extremes of life. The study was compared with various other studies conducted across India, as described in Table $10.17,18$

\begin{tabular}{|c|c|c|c|}
\hline Study & Male & Female & Age Group \\
\hline Saxena et al 16 & $86 \%$ & $14 \%$ & $20-40$ years \\
\hline Iqbal et al 17 & $81 \%$ & $19 \%$ & $21-30$ years \\
\hline Present Study & $82 \%$ & $18 \%$ & $21-40$ years \\
\hline \multicolumn{4}{|c|}{ Table 10. Various Studies showing Age and Sex } \\
Determinants
\end{tabular}

In our study, EDH was more commonly found in Males (82\%).

\section{Mode of Injury as Determinant}

The present study results are in concordance with other studies in reference to mode of injury, i.e. RTA followed by fall followed by assaults, which are compared and are shown in Table 11.

\begin{tabular}{|c|c|c|c|}
\hline Study & RTA & Fall & Assaults \\
\hline Saxena et al 16 & $72 \%$ & $17 \%$ & $5 \%$ \\
\hline Iqbal et al $^{17}$ & $40 \%$ & $44 \%$ & $14 \%$ \\
\hline Present Study & $60 \%$ & $25 \%$ & $15 \%$ \\
\hline \multicolumn{3}{|c|}{ Table 11. Mode of Injury as Determinant } \\
\hline
\end{tabular}

$66.67 \%$ of RTA occurred under influence of alcohol.

The dominant type of EDH observed in the study was fronto-temporoparietal with incidence of $25 \%$ cases followed by temporoparietal in $20 \%$ cases.

Pathak A et al reported from their study that the dominant type of EDH observed was temporoparietal in $43 \%$ cases followed by temporal in $21 \%$ of cases followed by frontal in $17 \%$ of cases. $40 \%$ cases presented with associated skull bone (64\%, Pathak A et al) fracture, both linear and comminuted. $15 \%$ cases of brain parenchyma injury in the form of $(10 \%$ Saxena et al) contusion, IVH (intraventricular haemorrhage) subdural haemorrhage and brainstem contusion excluding bony fracture together constituting 55\% (75\% Pathak A et al).

In the present study among 100 cases, $75 \%$ of cases could reach the treating hospital within 12 hours and remaining $25 \%$ cases after 12 hours. The study throws light in the significance of golden period in the management of extradural haemorrhage. ${ }^{18-23}$

$70 \%$ of cases presented with symptom of vomiting. The next prominent symptom being loss of consciousness observed in $60 \%$ cases and headache in $45 \%$ cases, which are the indicators of raised intracranial pressure, ENT bleeding constitutes 38\%; $8 \%$ had convulsion and $13 \%$ had hemiparesis symptoms.

On initial clinical examination $42 \%$ cases had Glasgow coma scale score of $15 / 15,24 \%$ with range of $13-14,20 \%$ with range of 9-12, 8\% with range of 8-5, 6\% in range of 3-4.

$70 \%$ had normal equally reacting pupils, $20 \%$ unequal and non-reacting, $10 \%$ bilateral dilated and fixed status as shown in Table 12.

\begin{tabular}{|c|c|c|c|c|c|}
\hline Study & & $\begin{array}{c}\text { GCS } \\
\text { Score }\end{array}$ & $\begin{array}{c}\text { Pupil } \\
\text { Status }\end{array}$ & \\
\hline & $9-15$ & $5-8$ & $3-4$ & E/R & Dil/NR \\
\hline $\begin{array}{c}\text { Saxena } \\
\text { study } 16\end{array}$ & $54 \%$ & $35 \%$ & $12 \%$ & $73 \%$ & $27 \%$ \\
\hline $\begin{array}{c}\text { Present } \\
\text { study }\end{array}$ & $86 \%$ & $8 \%$ & $6 \%$ & $70 \%$ & $10 \%$ \\
\hline \multicolumn{7}{|c|}{ Table 12. Comparison of Clinical Determinant } \\
with other Studies \\
\hline
\end{tabular}

After initial resuscitation in appropriate cases, an emergency CT scan was obtained in all cases and found to have positive finding which was added by follow-up CT scan. $58 \%$ cases presented with mass effect. $52 \%$ of cases underwent emergency decompressive procedure and evacuation of blood clot. Remaining $40 \%$ were managed conservatively as per medical line of management.

88 patients were recovered, whereas 12 patients were succumbed to death. 
In 8 cases ( $13 \%$ Gurupreeth et al), the head injury presenting as EDH was so severe that the victim could not survive even after emergency surgical intervention. They all presented to emergency ward $>12$ hours of trauma with associated brain parenchyma injury and poor GCS score.

\section{CONCLUSION}

Road traffic accident is the most common causative agent for EDH accounting for $60 \%$. Alcohol influence is a significant correlation to the causation. $60 \%$ cases had history of loss of consciousness, "the hallmark symptom of extradural haemorrhage" which should be seriously considered while taking history. Majority of patients obtained medical attention within 12 hours of head injury; so the onset of trauma and delay in the treatment had greatly influenced the patient outcome. Golden hour concept should be made aware among all healthcare providers. The degree of brain injury and the GCS difference were notable factors that were significant in determining the functional outcome of EDH. Early presentation to hospital with better GCS has good clinical outcome with minimal disability.

\section{REFERENCES}

[1] Khan MJ, Shaukat A, Khalid M, et al. Surgical management and outcome analysis of extradural hematoma at combined military hospital Rawalpindi. Pakistan Armed Forces Med J 2009;59(1):1-4.

[2] Taussky P, Widmer HR, Takala J, et al. Outcome after acute traumatic subdural and epidural haematoma in Switzerland: a single-centre experience. Swiss Med Wkly 2008;138(19-20):281-5.

[3] Yurt I, Bezircioglu H, Ersahin Y, et al. Extradural haematoma: analysis of 190 cases. Turkish Neurosurg 1996;6:63-7.

[4] Bullock MR, Chesnut R, Ghajar J, et al. Surgical management of acute epidural haematomas. Neurosurgery 2006;58(Suppl 3):S2-S15.

[5] Babu ML, Bhasin SK, Kumar A. Extradural hematomaan experience of 300 cases. JK Science 2005;7:205-7.

[6] Husain M, Ojha BK, Chandra A, et al. Contralateral motor deficit in extradural hematoma: analysis of 35 patients. Indian J Neurotrauma (IJNT) 2007;4(1):41-4.

[7] Hutchinson J. Effusion of blood between bone and Dura mater. Lond Hosp Rep 1867;4:51.

[8] Cheung PS, Lam JM, Yeung JH, et al. Outcome of traumatic extradural haematoma in Hong Kong. Injury 2007;38(1):76-80.
[9] Agrawal A, Agrawal CS, Kumar A, et al. Outcome of traumatic extradural haematoma managed surgically: our experience. Nigerian J Ortho Trauma 2007;6(2):74-6.

[10] Paterniti S, Fiore P, Macri E, et al. Extradural haematoma report of 37 consecutive cases with survival. Acta Neurochir (Wien) 1994;131(3-7):20710.

[11] Bricolo AP, Pasut LM. Extradural hematoma: toward zero mortality- prospective study. Neurosurgery 1984;14(1):8-12.

[12] Lobato RD, Rivas JJ, Cordobes F, et al. Acute epidural hematoma: an analysis of factors influencing the outcome of patients undergoing surgery in coma. J Neurosurg 1988;68(1):48-57.

[13] Dubey A, Pillai SV, Kolluri SVR. Does volume of extradural hematoma influence management strategy and outcome? Neurol India 2004;52(4):443-5.

[14] Mishra A, Mohanty S. Contre-coup extradural haematoma: a short report. Neurol India 2001;49(1):94-5.

[15] Cook RJ, Dorsch NW, Fearnside MR, et al. Outcome prediction in extradural haematomas. Acta Neurochir (Wein) 1988;95(3-4):90-4.

[16] Saxena RC, Bilodi AKS, Mane SS, et al. Study of pterion in skulls of Awadh area-in and around Lucknow. Kathmandu Univ Med J 2003;1(1):32-3.

[17] Iqbal Z, Arshad M, Yasin M. Acute traumatic extradural hematoma - a study of 80 cases. Pak J Neurol 1999;5:36-40.

[18] Kalayanaraman S, Ramamurthi K, Ramamurthi B. Analysis of 2000 cases of head injury. Neurology India 1970;18:3-11.

[19] Jamesson KG. Extradural and subdural haematoma, changing pattern and requirement of treatment in Australia. J Neurosurg 1970;33:632-5.

[20] Baykaner K, Alp H, Ceviker N, et al. Observations of 95 patients with extradural haematoma and review of literature. Surg Neurol 1988;30(5):339-41.

[21] Dufour H, Metellus P, Manera L, et al. Spontaneous vertex extradural hematoma: considerations about causes. Case report and review of the literature. J Neurosurg 2001;94(4):633-6.

[22] Carroll TA, Smith K, Jakubowski J. Extradural haematoma following temporomandibular joint arthrocentesis and lavage. $\mathrm{Br} \mathrm{J}$ Neurosurg 2000;14(2):152-4.

[23] Bae DH, Choi KS, Yi HJ, et al. Cerebral infarction after traumatic brain injury: incidence and risk factors. Korean J Neurotrauma 2014;10(2):35-40. 